\title{
Developing Eco-Driving Strategies considering City Characteristics
}

\author{
J. F. Coloma $\mathbb{D}^{1},{ }^{1}$ M. Garcia $\left(\mathbb{D},{ }^{1}\right.$ A. Boggio-Marzet $\left(\mathbb{D},{ }^{2}\right.$ and A. Monzón $\mathbb{D}^{2}$ \\ ${ }^{1}$ Betancourt Research Group, Universidad de Extremadura, Caceres 10003, Spain \\ ${ }^{2}$ Transport Research Centre, Universidad Politécnica de Madrid, Madrid 28040, Spain \\ Correspondence should be addressed to J. F. Coloma; jfcoloma@unex.es
}

Received 20 December 2019; Revised 10 July 2020; Accepted 18 July 2020; Published 3 August 2020

Academic Editor: Rocío de Oña

Copyright (c) 2020 J. F. Coloma et al. This is an open access article distributed under the Creative Commons Attribution License, which permits unrestricted use, distribution, and reproduction in any medium, provided the original work is properly cited.

$\mathrm{CO}_{2}$ emissions reduction is a top element of transport policy agenda. Among other mitigation policy measures, eco-driving techniques have proven to be effective in reducing fuel consumption and $\mathrm{CO}_{2}$ emissions. The aim of this paper is to compare the impacts of adopting eco-driving in different cities, road segments, traffic, and driver features. It intends to gain an insight into how city size and driving characteristics can reduce fuel consumption and $\mathrm{CO}_{2}$ emissions in order to develop specific eco-driving strategies. Field trials were conducted in two Spanish cities (Madrid and Caceres). 24 drivers, with different driving experiences, drove two different vehicles (petrol and diesel) along roads with different characteristics. The experiment was divided into two periods of 2 weeks; after the first one, drivers received an eco-driving training course. The impacts of eco-driving were measured comparing before and after results. They showed that eco-driving is highly effective in reducing fuel consumption and $\mathrm{CO}_{2}$ emissions in both, large-congested and small, cities. Savings between $5 \%$ and $12 \%$ were achieved. The efficiency increases with road capacity and decreased with city size. Eco-driving appears to be more effective in small, uncongested cities. In addition, limiting speeds on high capacity roads has proven to be a good energy saving measure.

\section{Introduction}

One of the challenges in the developed world is to promote low-carbon mobility models in terms of social equity and fair distribution of wealth. This is, in short, the challenge sustainability poses. As a result, sustainable mobility means ensuring our transport systems respond to economic, social, and environmental needs, thereby minimizing any detrimental impact they have [1].

According to the European Environmental Agency, greenhouse gas (GHG) emissions from transport have increased every year since 2014, being 29\% above 1990 levels in 2018 as a consequence of the growing demand in passenger and freight road transport $[2,3]$. Moreover, the share of renewable energy used for transport in the EU in 2018 was equal to $8.1 \%$, being below the EU target of $10 \%$ set for 2020 by the Renewable Energy Directive of 2009 [3]. This indicates that current efforts to limit the sector's environmental and climate impacts are not sufficient to meet the EU's long term policy objective.

Hence, to advance in our missions and accelerate the implementation of the Paris Agreement, the 25th session of the Conference of Parties of the United Nations Framework Convention on Climate Change, COP25 took place in Madrid in 2019. At this Conference, 73 nations (including Spain) have committed to become carbon neutral by 2050 [4]. The agreement calls for an increase in the ambition of climate change commitments, following the timetable set out in the Paris Agreement, which aimed to reduce GHG emissions by at least $40 \%$ by 2030 compared to 1990 .

The EU member states and the United Kingdom anticipate significant emission reductions in the transport sector from 2018 to 2030 , to be achieved through a wide range of measures such as vehicle efficiency, low-carbon fuels, electric vehicles, and modal shift [2]. Achieving the 2030 targets will require new and broader policies to increase 
energy efficiency in member states so they can keep their energy consumption under that limit [5].

In this context, countries may act in several key areas in order to reduce GHG emissions from transport. According to a comprehensive transport-sector, GHG reduction strategy should at least address the following key policies [6]:

(1) Reducing demand for transport: controlling land use to avoid car dependency and increasing occupancy rates.

(2) Mode share: measures aimed at promoting more environmentally friendly modes such as public transport and nonmotorised modes.

(3) Fuel choice: measures aimed at using technologies for alternative fuels and new energy sources other than petrol.

(4) Fuel efficiency: promoting efficient technologies for vehicles and traffic management, traffic congestion abatement measures, and eco-driving.

These four policies to reduce GHG can only be achieved with a global societal compromise. It should be fostered and sustained through awareness actions, targeted to all sectors. The fourth policy depends particularly on individual travel decisions and on driving styles. Eco-driving aims to improve driving efficiency by limiting velocity, showing fuel consumption, and $\mathrm{CO}_{2}$ reductions around $10 \%$ depending on corridor parameters (including traffic volume and speed) [7]. In addition, eco-driving achieved significant improvements on air quality when drivers utilize a slower route although they spend additional travel time [8].

Within this framework, eco-driving has emerged as the operational decision of drivers to maximize fuel efficiency and, consequently, reduce GHG emissions [9]. The literature shows that the efficiency of eco-driving varies widely depending on external circumstances and learning methods [10]. Reductions in $\mathrm{CO}_{2}$ emissions before and after receiving eco-driving instruction in several field trials varied from $0.5 \%$ to $10 \%$ depending on the type of road, e.g., motorways or urban roads [11]. Traffic flows and road slope as external factors had a direct influence on eco-driving efficiency [12]. Therefore, eco-drivers should adopt specific strategies according to the features of their city, different road conditions, and traffic volumes.

The most commonly applied method for individual drivers to implement eco-driving consists of training programmes that teach drivers theoretical and practical trainings. At a practical driving level, efficient fuel consumption implies smooth acceleration and braking, gear changes at low engine revolutions, and maintaining a constant speed avoiding sudden braking and acceleration. Fuel savings obtained after attendance at training programmes are heterogeneous, depending on the design of the training programme and the individuals' performance [13].

Most of the research carried out so far have focused on measuring very specific impacts from particular types of car or in specific cities, e.g., Seedam et al. [14] studied motorcycles in Thailand, Chen et al. [15] studied taxicabs in China, Barth et al. [16] worked with American motorways, and
Zarkadoula et al. [17] investigated bus drivers on Greek urban roads. All these studies demonstrate the goodness of eco-driving; however, the results from these specific studies are very difficult to extrapolate to other urban contexts. Therefore, there are no eco-driving studies in the literature that analyse its effectiveness in different types of city allowing to know the effect of its size or congestion levels.

The aim of this research is to compare eco-driving global effects by adopting this technique in two different cities as different as Madrid and Caceres (both located in Spain). It intends to gain an insight into how city size and driving characteristics affect eco-driving. Therefore, its goal is to compare general changes in fuel consumption, $\mathrm{CO}_{2}$ emissions, and driving patterns according to different types of city in order to develop specific eco-driving strategies. To obtain unbiased global objective data, it will be necessary to carry out the test with different roads and vehicle types, driving under various weather conditions with drivers of different characteristics.

After this introduction, Section 2 presents the methodology for testing the effects of eco-driving in both cities. Section 3 analyses the results and compares them with previous studies. Then, in Section 4, some policy recommendations are given based on these results.

\section{Methodology}

This paper evaluates the short-term impacts of an ecodriving training programme. Field trials were conducted in both Madrid and Caceres, which are in the centre and west of Spain. 24 drivers, who were male and female, with different driving experiences, drove vehicles, one of which was powered by petrol and the other by diesel along different types of roads at various periods of time for one month. By comparing scenarios (before and after the eco-driving training), fuel savings and reductions in $\mathrm{CO}_{2}$ emissions were analysed according to road sections and the cities under consideration. Figure 1 shows the methodological framework adopted in this research.

As mentioned above, this research was based on a case study in which data was collected through a real data collection campaign. The methodological framework consisted in three steps extensively described in the following sections, which were data acquisition, dataset creation through data processing and filtering, and results analysis by evaluating impacts before and after training for eco-driving.

Firstly, two eco-driving tests were carried out, one in Madrid, the other in Caceres. Note, Madrid, with a population of 6.6 million, is the capital of Spain, while Caceres, with only 96,000 inhabitants, is relatively small. Thus, these cities had different road characteristics and traffic flows.

After the data collection campaign, by implementing an energy consumption model, instantaneous data recorded were processed in order to determine specific eco-driving strategies according to different types of city and roads (see Sections 2.5 and 2.6). The result analysis focused on the impact of eco-driving in terms of changes in fuel consumption and $\mathrm{CO}_{2}$ emissions between Period 1 (before ecodriving training) and Period 2 (after training). 


\begin{tabular}{|c|c|c|}
\hline \multirow{2}{*}{$\begin{array}{c}\text { Data } \\
\text { acquisition }\end{array}$} & The dataset & Results \\
\hline & 128 Instantaneous variable & Eco-driving efficiency \\
\hline \multirow{3}{*}{$\begin{array}{l}24 \text { drivers } \\
2 \text { cities } \\
1,022 \text { journeys } \\
\text { eco-driving training }\end{array}$} & 9,760 km analyzed & depending on city and \\
\hline & & road section \\
\hline & (1) Selection of road sector & \\
\hline (i) OBD-key, ArcGis & (iii) VSP model & different scenarios \\
\hline
\end{tabular}

FIGURE 1: Research framework.

2.1. Experimental Setting. The experiment consisted in a field trial in Madrid and Caceres which took place from April-May 2017. Each of the 24 drivers involved in the experiment drove along pre-established routes. The test was initially performed for 2 weeks and drivers drove as they normally did (first period). Then, after they attended theoretical and practical training for eco-driving (see Appendix A), a second test (which also lasted a fortnight) was performed. Only this time eco-driving techniques were adopted and the same itineraries as in the first driving period were followed. Two categories of vehicle were used in the experiment: a diesel-powered Opel Astra $1.6 \mathrm{~L}$ and a petrolpowered Fiat 500 1.2 L.

12 drivers were recruited for each city. Driving shifts lasted 4 hours; each one covered by a pair of drivers who alternated driving every 2 hours. 3 driving shifts per day of 4 hours each, from 8.00 am to $8.00 \mathrm{pm}$ (only workdays), enabled us to collect a large amount of real data along different stretches of road under different traffic conditions. Data with regards to GPS position speed and engine parameters, as well as operational conditions, were collected by the second through a preinstalled device in each vehicle (see Section 2.5).

The experiment is carried out with different vehicles, drivers, and road types to obtain global results. It took place in April-May, which in Spain is spring, with mild temperatures around $20^{\circ} \mathrm{C}$. Driving was done mostly in sunny weather conditions. Exceptionally, moments of fog and rain were recorded but did not produce significant changes in the experiment results.

2.2. Route Selection. During the data collection campaign, 24 drivers drove diesel or gasoline vehicles along pre-established routes, before and after attending training for ecodriving. Ten different itineraries, which covered several alignments and types of road (e.g., local street, urban collector, major arterial, and motorway), were selected for the field test-six in Madrid and four in Caceres. Figure 2 shows the location of the field trials in both cities.

As the main goal of this research consisted in creating different eco-driving strategies according to city size, for purposes of consistency, the whole itineraries covered during the field trials have not been considered. In fact, in our analysis, we only looked at the same types of road in both Madrid and Caceres, which are local street and major arterial [18]. Local streets are urban roads with a single traffic lane and level intersections with traffic lights or adequate signage. Major arterials are high capacity urban roads with $2 \times 2$ lanes separated by a barrier where the level intersections are made with roundabouts. Major arterials provide more mobility, but local streets provide more access. The results obtained from the analysis of data recorded along these types of road were used to compare how effective eco-driving was in both cities. Table 1 shows their main characteristics.

2.3. Case Study in Madrid. Madrid is the capital of Spain. Located in the heart of the Iberian Peninsula, the metropolitan area of Madrid covers $8,022 \mathrm{~km}^{2}$ of built-up land and has a population of 6.6 million. Three orbital motorways encircle the city (the M-30, M-40, and M-50) which are accessed from seven radial motorways [19].

The data collection campaign focused on the connection between Madrid and two interurban municipalities of the capital city, Pozuelo and Majadahonda. Thus, two itineraries, both located in the northwest of the city with different stretches of road and alignments, were selected to ensure a variety of driving and traffic characteristics in the sample. Both itineraries were characterized by having gentle slopes and connected the civil engineering school of "Universidad Politécnica de Madrid” (UPM) with two municipalities in the Madrid Metropolitan Area (Pozuelo and Majadahonda), where $92 \%$ of daily trips are made by car [20]. The area suffers chronic congestion, particularly at peak hours, affecting more to local roads than high capacity major arterial sections.

In Madrid, 12 drivers were involved in the data collection campaign. The sample was made up of seven males and five females aged between 23 and 50, with different driving experiences, between April 17th and May 19th, 2017. During the data collection campaign, $7,288 \mathrm{~km}$ of road were recorded in Madrid. 3,691 km during the first driving period and $3,597 \mathrm{~km}$ during the second one as eco-driving was implemented.

The routes covered were composed of different stretches of road, local roads or motorways, with different longitudinal and transverse profiles and characterized by having different speed limits. Thus, when comparing Caceres and Madrid, we only considered those stretches of the itineraries with the same types of road in both cities when extracting our results; i.e., local street and major arterial.

2.4. Caceres Case Study. It is a small city, which can be crossed in under 15 minutes by any itinerary. Two alternative routes (local street and major arterial) with different road capacities were chosen for comparing results with 


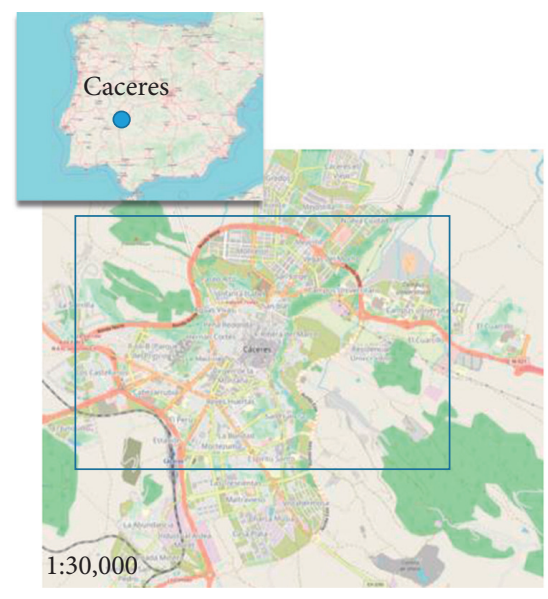

(a)

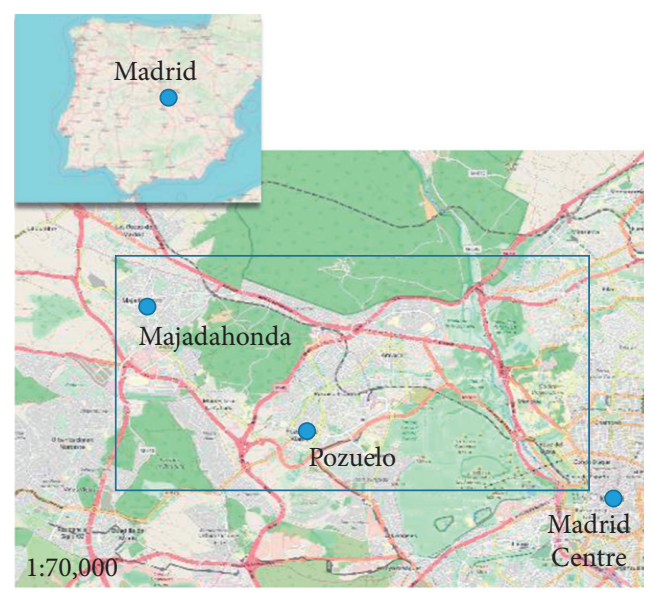

(b)

Figure 2: Location of the field trials in Caceres and Madrid, Spain.

TABLE 1: Information on driving urban routes tested in both cities.

\begin{tabular}{lcccccc}
\hline City & Road section & Lanes & Speed limit $(\mathrm{km} / \mathrm{h})$ & Distance $(\mathrm{km})$ & Driving time $(\mathrm{min})\left({ }^{*}\right)$ & Average slope $(\%)$ I/II $(* *)$ \\
\hline \multirow{2}{*}{ Madrid } & Local street & $1 \times 1$ lanes & 50 & 12.00 & $17-30$ & $3.0 / 3.1$ \\
& Major arterial & $2 \times 2$ lanes and barrier & $30-50$ & 10.83 & $17-32$ & $3.1 / 3.2$ \\
\hline \multirow{2}{*}{ Caceres } & Local street & $1 \times 1$ lanes & 50 & 6.10 & 15 & $2.9 / 2.9$ \\
& Major arterial & $2 \times 2$ lanes and barrier & $40-80$ & 10.30 & 12 & $2.0 / 2.0$ \\
\hline
\end{tabular}

$\left({ }^{*}\right)$ nonpeak/peak hours. $(* *)$ direction I/direction II (inverse). Source: Google Earth.

Madrid. Both routes, which started at the university campus and ended at the train station, followed roads with different characteristics. The two routes with similar characteristics to those in Madrid are described below.

Local street: it is made up of urban roads that cross the city centre. The route is $6.1 \mathrm{~km}$ long and the speed limit is $50 \mathrm{~km} / \mathrm{h}$. Travel time is 15 minutes at an average speed of $23.6 \mathrm{~km} / \mathrm{h}$. There are several traffic lights, pedestrian crossings, and single-lane roads in both directions.

Major arterial: it is a recently built bypass which encircles the city. It has a section of urban motorway with level intersections with roundabouts. It is $10.3 \mathrm{~km}$ long and speed limits vary from 40 to $80 \mathrm{~km} / \mathrm{h}$. Travel time is 12 minutes at an average speed of $39.4 \mathrm{~km} / \mathrm{h}$.

In Caceres, the experiment took place from May 2nd to May 26th, 2017. During the data collection campaign, $2,472 \mathrm{~km}$ of road were recorded. The first $1,234 \mathrm{~km}$ driven was noneco (first period) and the next $1,238 \mathrm{~km}$ was ecodriving (second period). The sample was composed of 12 drivers, 8 males, and 4 females aged between 21 and 44 years [21].

2.5. The Dataset Creation. Eco-driving was tested under real traffic conditions (free floating itineraries). During the data collection campaign, data were recorded by the second through an on-board logging, preinstalled device in each vehicle [22]. This gave us the instantaneous values of GPS position, speed, engine parameters, and operational conditions throughout the whole test. This device is easily installed in the vehicle diagnostic port and sends the data to a mobile phone via Wi-Fi with a frequency of $1 \mathrm{~Hz}$. A mobile application [23] was used to collect this information and enabled the data to be downloaded onto a standard spreadsheet, which was subsequently exported to a laboratory computer (Figure 3 ).

Once all data were recorded, the VSP-Vehicle Specific Power model [24] was used for estimating instantaneous fuel consumption and $\mathrm{CO}_{2}$ emissions for each vehicle (for further details, see Section 2.6). Then, the data was processed and statistical values were calculated with the R 3.6.0 software [25]. Before processing the data, a series of filters were applied to detect erroneous position and speed data due to unscheduled detours of routes or due to GPS malfunction. Using the ArcGis software [26], we could split up each itinerary covered into homogeneous stretches of road. On this basis, we could analyse the results according to types of road, later on.

Itineraries covered during the data collection campaign were composed of several sections of road, i.e., urban motorway, collector, major arterial, and local street. The purpose of this research was to gain an insight into how city size and driving characteristics affected fuel consumption and $\mathrm{CO}_{2}$ emissions. In addition, in order to develop specific eco-driving strategies, we only took into account parts of the itineraries in which there were sections of road common to both cities. Thus, we only selected data on local street and major arterial roads.

The sample selected was composed of 1,022 trips, or $9,760 \mathrm{~km}$ of road $(4,925 \mathrm{~km}$ in period 1 and $4,835 \mathrm{~km}$ in period 2 ), each one measured by the second with 128 different variables. 
Vehicle

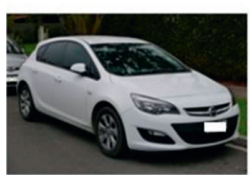

OBD-key bluetooth

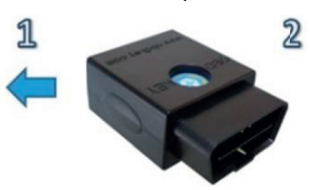

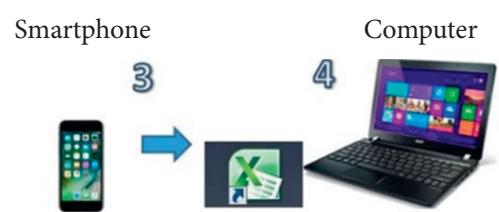

Figure 3: Data acquisition equipment.

2.6. Fuel Consumption and Emission Calculation. During the data collection campaign, data on GPS positions and instantaneous speed were recorded with an OBD-key preinstalled in each vehicle. The consumption values obtained with this device turned out to be different from the real consumption recorded on the petrol station receipts. Therefore, after an initial data processing stage with $\mathrm{R}$ programming, instantaneous fuel consumption was calculated on the basis of the VSP-Vehicle Specific Power model [24], which is a convenient direct estimate of the power demand on an engine whilst driving. The model is a validated methodology which characterizes vehicles and driving profiles using real-world data $[27,28]$. VSP represents the ratio between the power demands of the vehicle and its mass, so it can be used for different types of powered vehicles (diesel [29], petrol [30], and electric [31]). Given the instantaneous speed, acceleration and road slope, this model shows instantaneous power demands of the vehicle according to (1), developed by Jimenez-Palacio [24]:

$$
\begin{aligned}
V S P\left[\frac{\mathrm{W}}{\mathrm{kg}}\right] & =\frac{\text { Power }}{\text { Mass }}=\frac{(d / d t)\left(E_{\text {kinetic }}+E_{\text {potential }}\right)+F_{\text {rolling }} * v-F_{\text {aerodynamic }} * v}{m} \\
& =v(1.1 * a+9.81 * \text { grade }+0.132)+3.02 * 10^{-4} * v^{3},
\end{aligned}
$$

in which VSP is vehicle specific power (W/ kg), $E_{\text {kinetic }}$ is kinetic energy $(\mathrm{J}), E_{\text {potential }}$ is potential energy $(\mathrm{J}), F_{\text {rolling }}$ is rolling resistance force $(\mathrm{N}), F_{\text {aerodynamic }}$ is aerodynamic resistance force $(\mathrm{N}), v$ is instantaneous speed $(\mathrm{m} / \mathrm{s}), m$ is mass $(\mathrm{kg}), a$ is acceleration $\left(\mathrm{m} / \mathrm{s}^{2}\right)$, and grade is road grade $(\mathrm{m} / \mathrm{m})$.

VSP depends on speed, acceleration, and grade. As shown in Figure 4, a higher-grade rating means more power is needed and more fuel used. The same effect occurs with greater speed or acceleration. On the contrary, if acceleration or grade increase for a certain speed, higher energy consumption is required as well.

VSP $(\mathrm{W} / \mathrm{Kg})$ was calculated each second of driving and it was associated to one "VSP mode," which corresponded to a certain interval of power requirements (Table 2), according to Faria et al. [32]. The VSP mode define the possible combination of different driving and road conditions.

VSP mode sets driving ranges from low to high energy consumption. VSP mode 1 and 2 mean negative VSP values. These values are obtained when the car is running through negative slope and the accelerator is not pressed. Performance of these VSP categories are not stable delivering fuzzy results. VSP mode 3 means small positive values, which rarely happens since small speeds are usually linked to large accelerations/decelerations. VSP mode 4 is one of the modes that occur most frequently since it deals with common relationship between speed and acceleration. Finally, VSP mode 5 to 11 involve higher accelerations and speeds, so they typically occur less frequently, when starting a section with slope, or when overtaking another car or lorry.

Once the corresponding VSP mode was obtained by the second, each of them could be correlated with energy consumption according to vehicle engine and segmentation [32]. From these values and those for light vehicles, we could estimate fuel consumption with the relationship $1 \mathrm{~L}$ pet$\mathrm{rol}=32.2 \mathrm{MJ}$ and $1 \mathrm{~L}$ diesel $=35.9 \mathrm{MJ}$ [33]. In light of this VSP mode, Coelho et al. [34] calculated $\mathrm{CO}_{2}$ emission rates for petrol and diesel cars of the same types that we used in this experiment. Their results are shown in Table 3.

The consumption and emissions data are not very consistent with each other, since they come from different studies. In our research, we have given it as valid since our goal is not to accurately estimate the $\mathrm{CO}_{2}$ emissions produced by each car at any given time. We are looking for a comparison between efficiency of eco-driving in different cities in percentages and not in absolute terms.

By using this methodology and taking advantage of the high resolution of real driving data outputs (collected every second), we could evaluate how driving behaviour influences fuel consumption and emissions. This was fundamental to our research and enabled us to associate emissions with the different routes involved, as well as fuel consumption and eco-driving efficiency according to city size.

\subsection{Selection of Parameters to Measure Eco-Driving Impacts.} The evaluation of the impacts of eco-driving focused on the differences in fuel consumption and $\mathrm{CO}_{2}$ emissions between period 2 (after eco-driving training) and period 1 (before eco-driving training). It must be stressed that the aim of this research was not to obtain exact values for consumption or emissions, but to compare the efficiency of eco-driving according to types of routes or cities. 


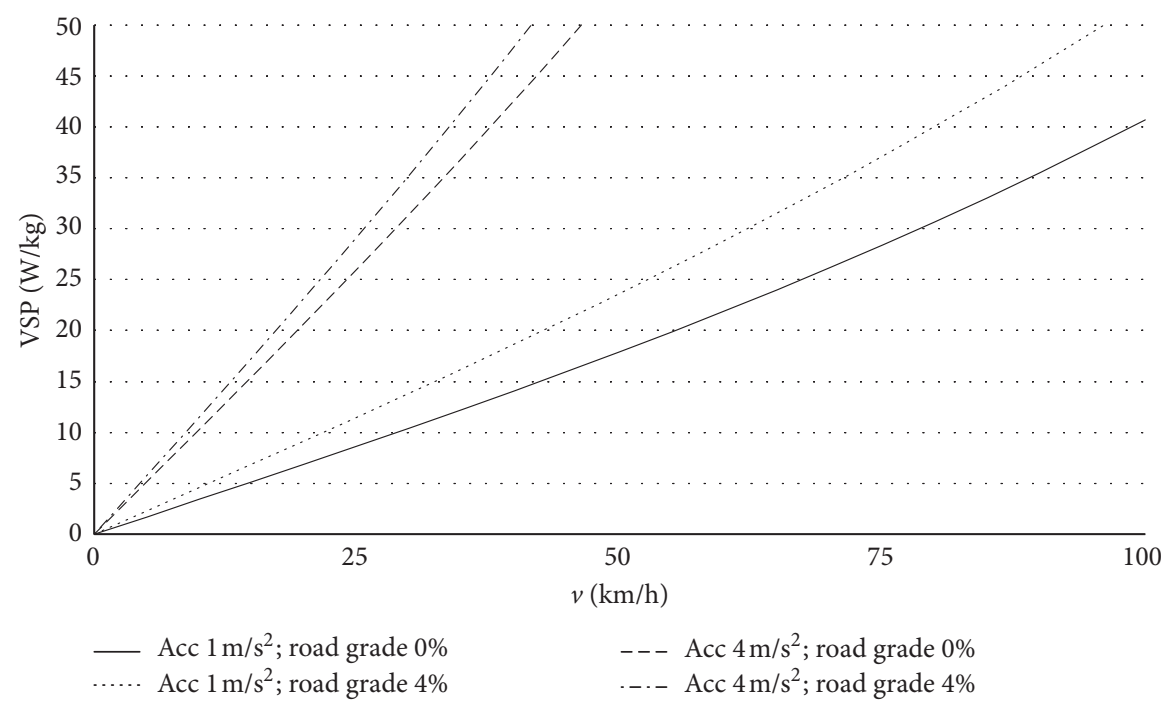

FIgURE 4: VSP for different slopes, speeds, and acceleration.

TABLE 2: Correlation between VSP (power requirements in W/Kg) and "VSP mode."

\begin{tabular}{lcc}
\hline Vehicle specific power VSP $(\mathrm{W} / \mathrm{kg})$ & VSP mode & Driving and road conditions \\
\hline$<-2$ & 1 & Negative slope, no acceleration \\
{$[-2,0)$} & 2 & Low acceleration for increasing speed smoothly \\
\hline$[0,1)$ & 3 & \\
{$[1,4)$} & 4 & Rapid accelerations to reach higher speed \\
{$[4,7)$} & 5 & \\
{$[7,10)$} & 6 & \\
{$[10,13)$} & 7 & \\
{$[13,16)$} & 8 & \\
{$[16,19)$} & 9 & \\
{$[19,23)$} & 10 & \\
\hline
\end{tabular}

TABLE 3: Correlation between VSP mode, energy consumption, fuel consumption, and $\mathrm{CO}_{2}$ emissions.

\begin{tabular}{|c|c|c|c|c|c|}
\hline \multirow[t]{2}{*}{ VSP mode } & \multirow[t]{2}{*}{ Energy [32] consumption $\left(10^{-3} \mathrm{MJ} / \mathrm{s}\right)$} & \multicolumn{2}{|c|}{$\begin{array}{l}\text { Instantaneous fuel } \\
\text { consumption }\left(10^{-4} 1 / \mathrm{s}\right)\end{array}$} & \multicolumn{2}{|c|}{$\mathrm{CO}_{2}$ emissions (g/s) [34] } \\
\hline & & Petrol & Diesel & Petrol & Diesel \\
\hline 1 & 4.0 & 1.244 & 1.116 & $0.63\left(^{*}\right)$ & $0.21\left(^{*}\right)$ \\
\hline 2 & 6.0 & 1.866 & 1.674 & 1.05 & 0.61 \\
\hline 3 & 6.6 & 2.053 & 1.841 & 1.02 & 0.73 \\
\hline 4 & 20.0 & 6.220 & 5.580 & 2.07 & 1.50 \\
\hline 5 & 27.0 & 8.397 & 7.533 & 2.79 & 2.34 \\
\hline 6 & 37.0 & 11.507 & 10.323 & 3.47 & 3.29 \\
\hline 7 & 46.0 & 14.306 & 12.834 & 4.31 & 4.20 \\
\hline 8 & 54.0 & 16.794 & 15.066 & 5.19 & 4.94 \\
\hline 9 & 64.0 & 19.904 & 17.856 & 5.81 & 5.57 \\
\hline 10 & 73.0 & 22.703 & 20.367 & 6.43 & 6.26 \\
\hline 11 & 88.0 & 27.368 & 24.552 & 7.37 & 7.40 \\
\hline
\end{tabular}

$(*)$ these values from [34] are very inconsistent. They will be used only for calculating variation in percentage.

The effects of the training programme in terms of changes in driving patterns and reductions in fuel consumption are first checked according to vehicles, drivers, and types of road in both cities. Fuel consumption depends on driving style and traffic context on each road segment. An exploratory factor analysis was carried out to identify the main underlying factors related to driving elements, grouping the variables with high factor loadings [35]. A 
multiple regression was conducted to examine the effect on fuel consumption in order to rank the hierarchical structure among driving pattern and road environment factors. This multiple regression shows the association of variables and defines four factors which explain a variance of $81.7 \%$ of the trip variables. Average speed, average rpm, positive acceleration over $0.83 \mathrm{~m} / \mathrm{s}^{2}$, and negative acceleration under $-0.83 \mathrm{~m} / \mathrm{s}^{2}$ were the four factors closely associated with fuel consumption throughout the trip [36]. We thus considered variables related to fuel consumption, emissions, and driving patterns.

Table 4 shows an overview of the selected parameters to measure inputs and outputs, their units, and corresponding abbreviations. Driving performance is explained by the parameters that are extracted directly from the OBD-Key, and fuel consumption and emissions respond to parameters that are obtained after applying the VSP method.

\section{Analysis of Results}

The analysis of the outputs shows how the different elements interact with each other: eco-driving skills, type of road, and city characteristics, to change energy consumption and consequently $\mathrm{CO}_{2}$ emissions. Firstly, energy efficiency (VSP modes and energy consumed) is analysed by the type of route and city characteristics. Secondly, the overall impact of eco-driving training regardless of the city is explored, along with changes in driving performance. Finally, it shows specific effects according to the two types of road selected in Madrid and Caceres in order to research the combined influence of city size and eco-driving in different city contexts.

Experimental statistics of distances driven by route, vehicle, and driving period are shown in Table 5.

The $9,760 \mathrm{~km}$ travelled have been distributed in a homogeneous way between eco and noneco-driving styles. However, this balance is not maintained in the type of road travelled since $69 \%$ has been done on local street and $31 \%$ on major arterial. This difference is due to the fact that Madrid has a bigger share of urban highways than Caceres, which is a small city, where most of the itineraries are local. For the shake of correct comparison, we have only selected the road sections which are common to both cities to compare the effectiveness of eco-driving between the two cities.

3.1. Energy Efficiency according to Route and City Characteristics. Figure 5 shows the average VSP profiles broken down by cities and types of road in the experiment. Drivers in both cities spent a big share on driving time in VSP modes 1-4, while higher accelerations were less used.

Caceres major arterial shows different behaviours to the other routes, since there is no marked peak at VSP mode 4 and there are bigger percentages of time at high VSP modes (bands 7-11). This difference is due to the speed limits on this route. Recorded maximum speeds are higher than speed limit $(80 \mathrm{~km} / \mathrm{h})$. Enforcement is not so effective being a small city. Therefore, there are higher energy consumption on many stretches.
Figure 6 shows average energy consumption per kilometre and average speed for each road and type of city.

Figure 6 shows that roads where average speed is higher obtain better results on average energy consumption. This is because lower velocity means more congestion and therefore greater more energy consumption.

Caceres major arterial shows a high percentage of time (almost 30\%) in VSP mode 1, so the final average values obtained for energy consumption are lower than those for the two local routes in Madrid and Caceres. Nevertheless, it showed more energy consumption than that recorded for the major arterial in Madrid where the speed limit was $50 \mathrm{~km} / \mathrm{h}$. Therefore, from an energy-savings perspective, restricting speeds on high capacity roads seems to be a sensible measure to take.

3.2. Overall Impacts of Eco-Driving (after Training Course). Figure 7 shows the reduction in the different driving parameters analysed due to eco-driving on the two types of road common to Madrid and Caceres.

Fuel consumption and $\mathrm{CO}_{2}$ emissions were always lower when eco-driving, and savings were bigger on higher capacity roads (major arterial). Savings values were between $5 \%$ and $12 \%$, which were similar to values from other studies. Rolim et al. [37] and Beusen et al. [38] obtained fuel savings for light vehicles of around 5\% while Zarkadoula et al. [17] and Strömberg and Karlsson [39] reached values between 5 and 7\% for urban buses. Other authors such as Miller et al. [40] and Andrieu and Pierre [41] obtained higher savings from eco-driving, which surpassed 15\%.

Eco-driving led to important reductions in all the driving parameters analysed in this research. The highest savings were once again linked to higher road capacity sections, being "major arterial" road types which achieve more reduction values and, on the contrary, "local street" type of sections account for the lowest.

Accelerations and decelerations were the parameters which change most when drivers do eco-driving (36-52\%) while average speeds reductions were less marked (3-7\%). These values were similar to other ones in which reducing $\mathrm{CO}_{2}$ meant decreasing travel speed and increasing travel time [8]. Lower acceleration corresponds to nonaggressive driving styles which are associated to lower accidentality rates.

\subsection{Impacts of Eco-Driving according to City Size and Type of} Road. Figure 8 shows the reductions in fuel consumption and $\mathrm{CO}_{2}$ emissions from eco-driving in both cities and for the two types of road. The figure presents average and dispersion values, which logically present similar patterns for both analyses.

Madrid and Caceres showed reductions in consumption and $\mathrm{CO}_{2}$ emissions for all types of road, and the higher the road capacity was, the more savings there were. This suggests that eco-driving is less effective in congestion. Other studies such as those by García-Castro and Monzon [42] or PerezPrada et al. [43] in Madrid obtained negative effects on saturated roads. Furthermore, dual carriageways are highly 
TABLE 4: Description of the parameters selected for measuring effects of eco-driving.

\begin{tabular}{|c|c|c|c|}
\hline Parameter type & Description & Code & Unit \\
\hline Driving performance (OBD-key) & $\begin{array}{c}\text { Average speed } \\
\text { Average rpm } \\
\text { Time with acceleration over } 0.83 \mathrm{~m} / \mathrm{s}^{2} \\
\text { Time with deceleration under }-0.83 \mathrm{~m} / \mathrm{s}^{2}\end{array}$ & $\begin{array}{l}\text { avg_speed } \\
\text { avg_rpm } \\
\text { acc } \\
\text { dec }\end{array}$ & $\begin{array}{c}\mathrm{km} / \mathrm{h} \\
\mathrm{rpm} \\
\mathrm{s} \\
\mathrm{s}\end{array}$ \\
\hline Fuel consumption and emissions (OBD-Key + VSP) & $\begin{array}{l}\text { Average fuel consumption } \\
\text { Average } \mathrm{CO}_{2} \text { emissions }\end{array}$ & $\begin{array}{l}\text { avg_fc } \\
\text { avg_COCO }\end{array}$ & $\begin{array}{l}\mathrm{L} / \mathrm{s} \\
\mathrm{g} / \mathrm{s}\end{array}$ \\
\hline
\end{tabular}

TABLE 5: Km driven per vehicle, road type, and test period.

\begin{tabular}{|c|c|c|c|c|c|c|}
\hline \multirow{2}{*}{ Road type } & \multicolumn{3}{|c|}{ Non eco-driving (period 1 ) } & \multicolumn{3}{|c|}{ Eco-driving (period 2) } \\
\hline & Diesel & Petrol & Total km & Diesel & Petrol & Total km \\
\hline Local street & 1,592 & 1,802 & 3,394 & 1,698 & 1,616 & 3,314 \\
\hline Major arterial & 758 & 773 & 1,531 & 829 & 692 & 1,521 \\
\hline Total $\mathrm{km}$ per period & & & 4,925 & & & 4,835 \\
\hline Total km driven & & & & & & \\
\hline
\end{tabular}

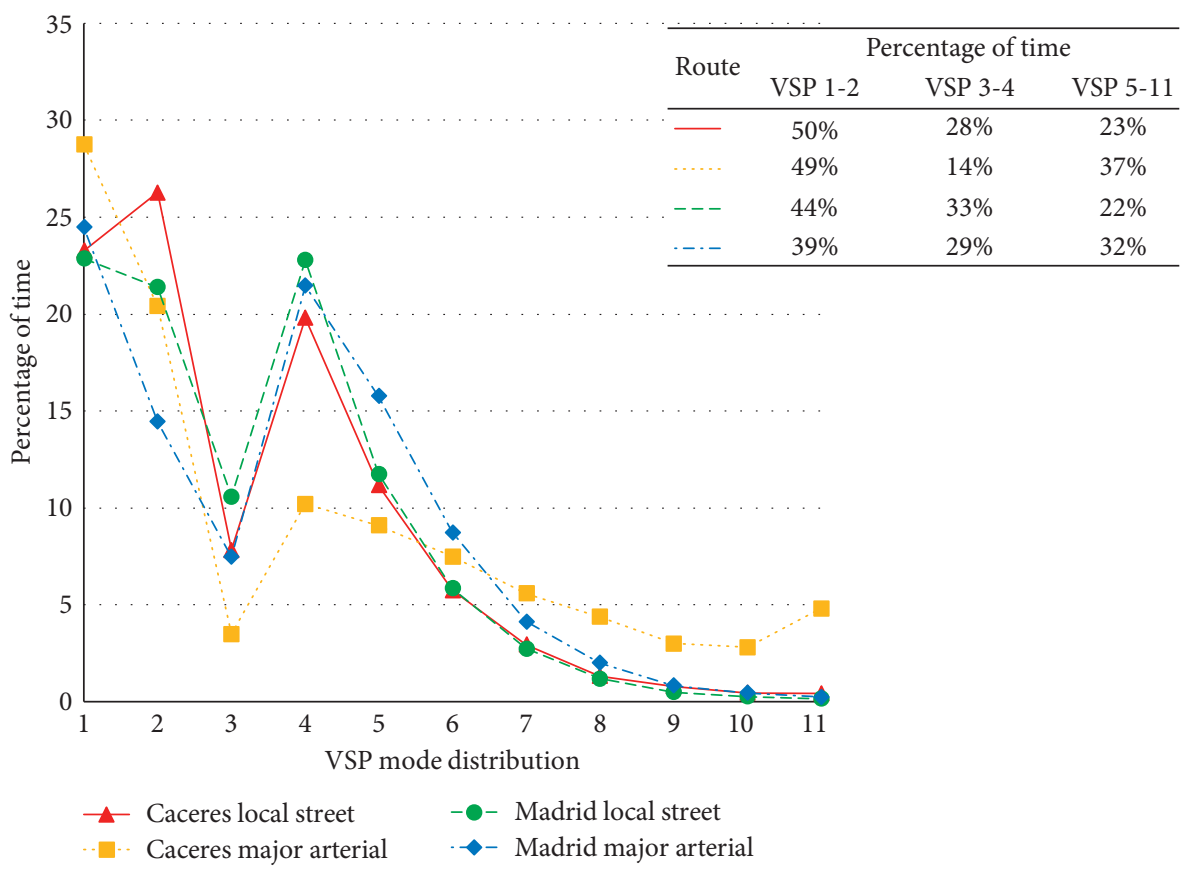

FIGURE 5: VSP mode distribution for different types of road and cities.

effective in terms of fuel consumption and $\mathrm{CO}_{2}$ emissions for major arterial roads.

The impacts of eco-driving on the other performance parameters are included in Figures 9-11. All of them-average speed, average $\mathrm{rpm}$, and acceleration and deceleration-are explanatory variables for fuel consumption, and therefore their reductions are consistent with the previous results. However, there are clear differences among them, depending of the type of road section and city size.

Figure 9 shows that eco-driving reduces the average speed of traffic in general on all types of road. These values were higher in Caceres than in Madrid, since they were less prone to the effects of traffic congestion. Caceres also showed higher speed reductions with higher road capacity. Barić et al. [44] obtained on local streets similar reduction values, which reached $1.64 \%$ after the eco-driving course and $2.62 \%$ three months later.

The range of legal speed limits on major arterial roads was higher than on local street. This produced a greater variation in noneco- and eco-speeds and hence greater dispersion in the error bars. In this respect, the values for Madrid were singular, since on major arterial roads average speeds did not fall with eco-driving. Average reduction values were obtained although these were very low compared to the other routes. On motorways, Barth and Boriboonsomsin [45] achieved speed average reductions of 


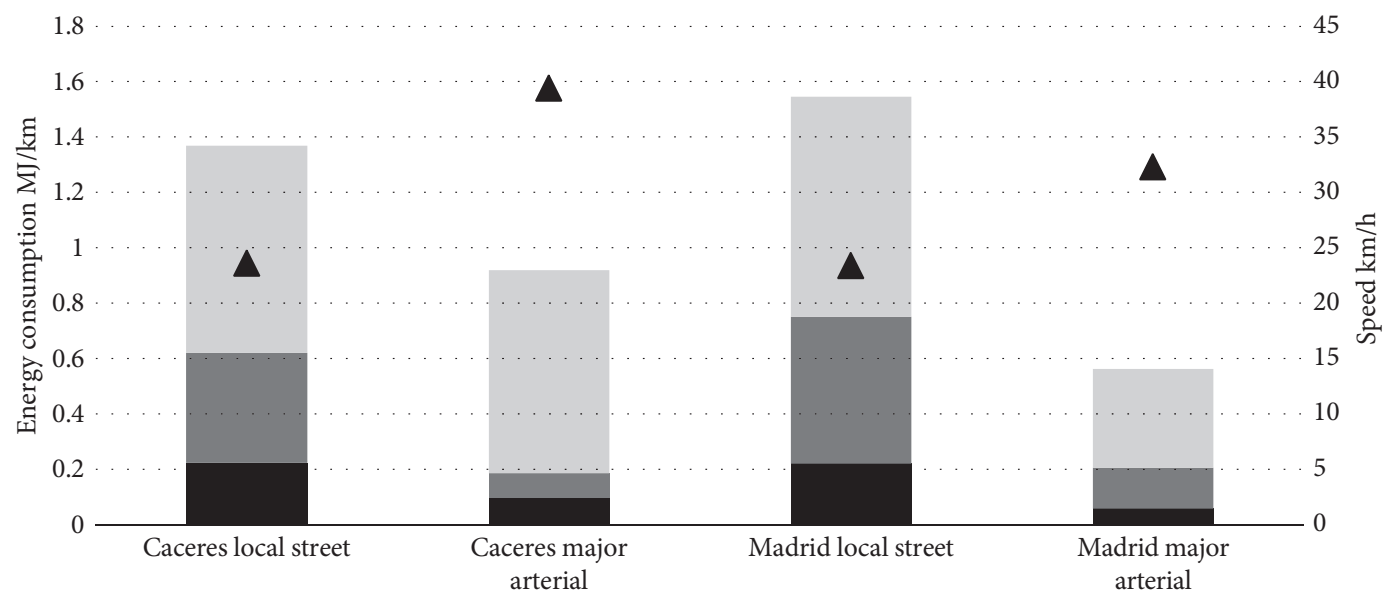

- VSP mode 1-2

VSP mode 3-4

(1- VSP mode 5-11

\ Average speed $\mathrm{km} / \mathrm{h}$

Figure 6: Average energy consumption $(\mathrm{MJ} / \mathrm{km})$ and average speed $(\mathrm{km} / \mathrm{h})$ for each city and type of road.

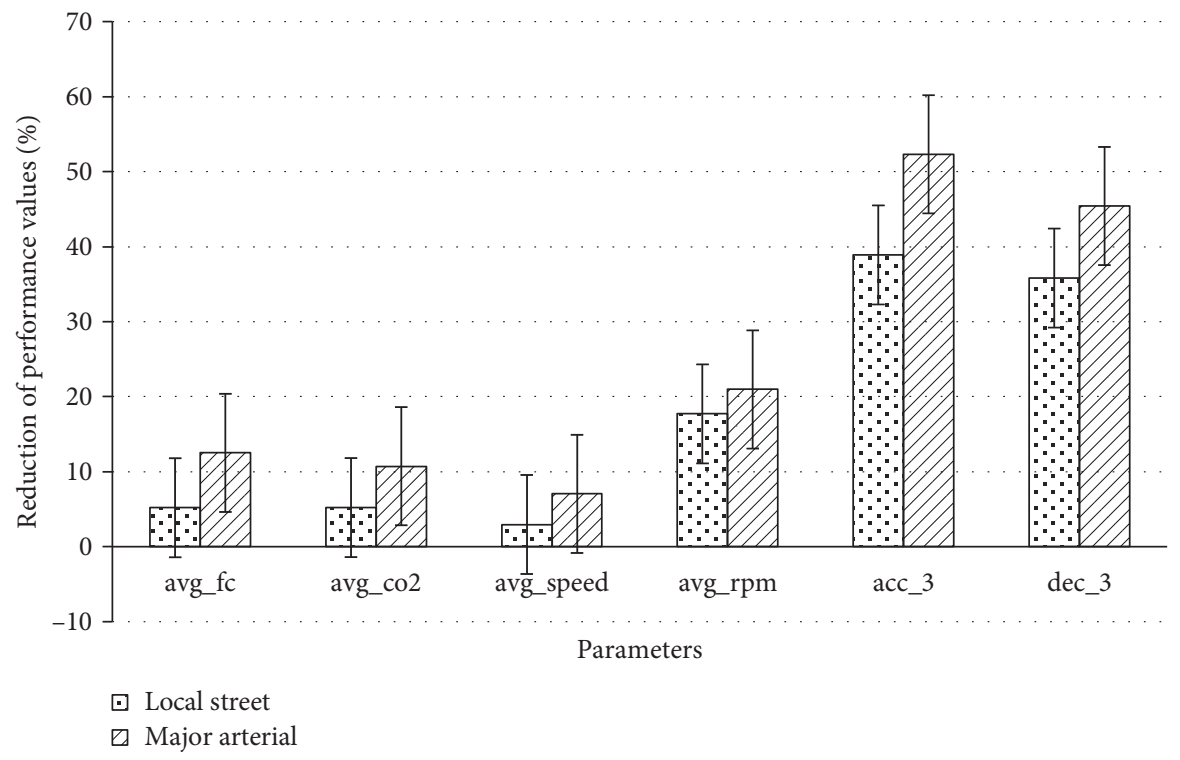

FigURE 7: Effects of eco-driving training on traffic and emissions parameters.

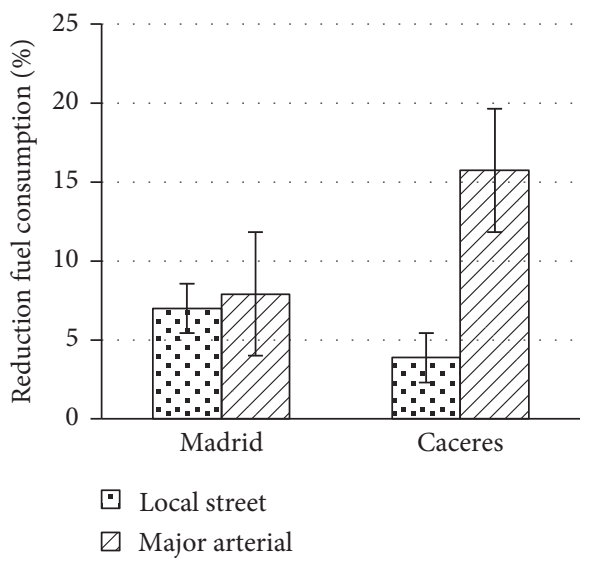

(a)

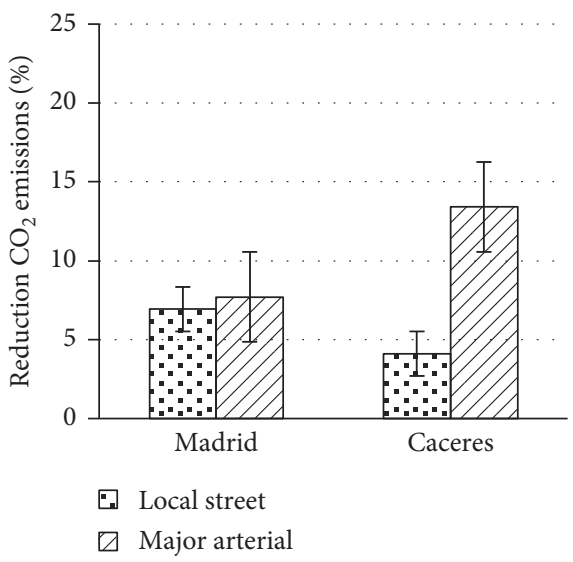

(b)

FIgURE 8: Impact of eco-driving in fuel consumption and $\mathrm{CO}_{2}$ emissions. 


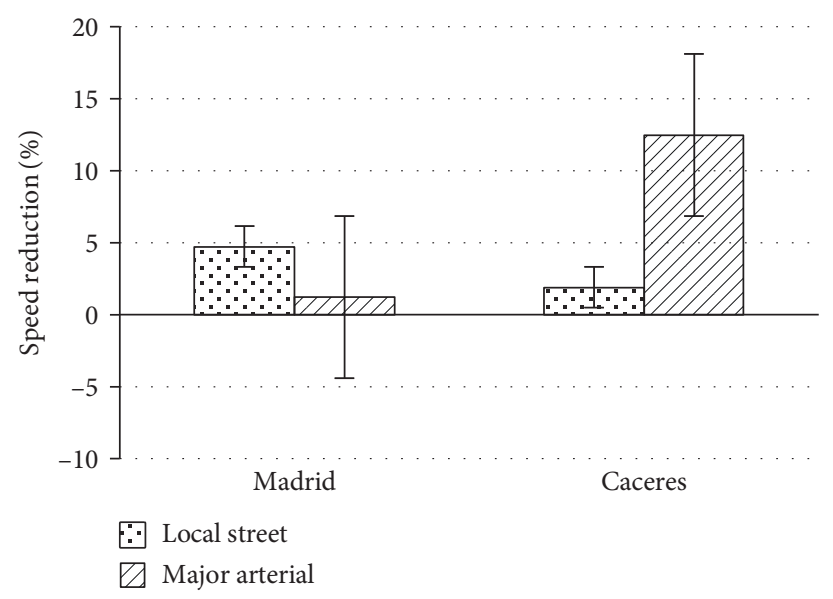

FIGURE 9: Impact of eco-driving on average speed.

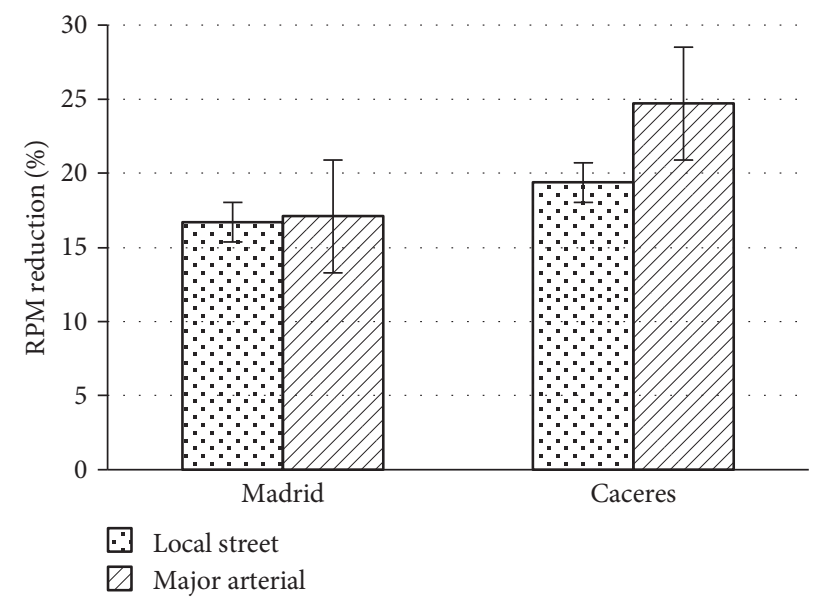

FIGURE 10: Impact of eco-driving on average rpm.

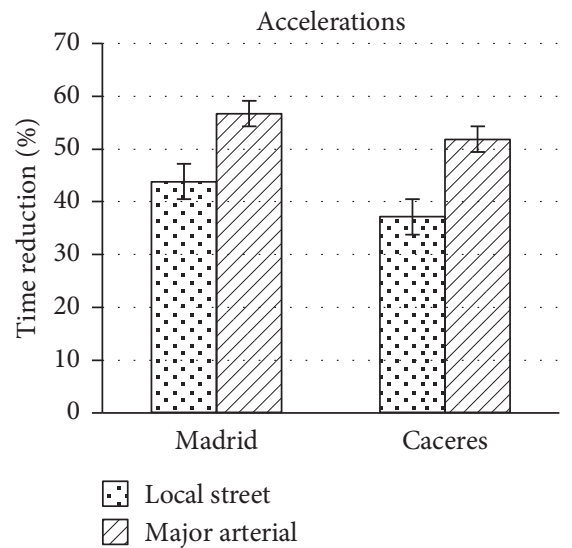

(a)

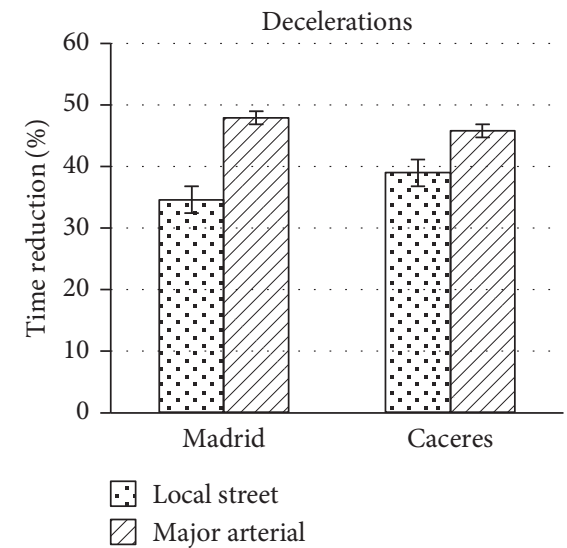

(b)

FIGURE 11: Impact of eco-driving in accelerations and deceleration higher than $0.83 \mathrm{~m} / \mathrm{s}^{2}$.

3.05\%, slightly higher to those obtained on Madrid major arterial roads.

From Figure 10, we can see significant reduction on average rpm in both cities and for all types of road with eco- driving, and with quite low dispersion levels. That means that once the driver starts eco-driving, his performance is quite stable, assuring constant results. This reduction was higher in the less congested city-Caceres-and increased 


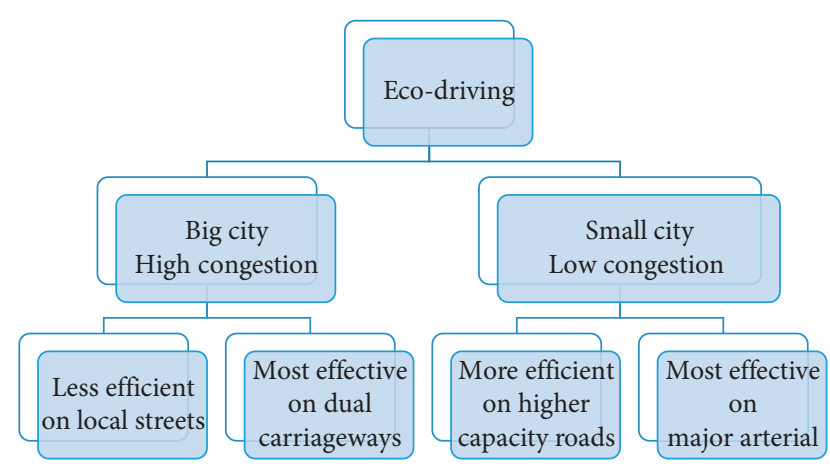

FIgURE 12: Eco-driving impacts in different types of city.

with road capacity, major arterial. This effect was normal in manual vehicles but Laure et al. [46] obtained a slight increase in rpm with an automatic one.

Finally, we analyse the impact of eco-driving on driving style (Figure 11), producing clearly smoother driving performance, reflected in $20-50 \%$ less values for the accelerations and decelerations indicators. On all types of road and in both cities, there were important reductions with ecodriving which were proportional to road capacity.

\section{Conclusions and Policy Recommendations}

4.1. Main Findings. One of the priority goals of the political transport agenda, particularly in developed countries, is to mitigate GHG produced by the large number of $\mathrm{CO}_{2}$. Ecodriving techniques can contribute to reduce these effects, with a modest but consistent reduction.

This research studies the effects of eco-driving on fuel consumption, $\mathrm{CO}_{2}$ emissions, and driving parameters in two very different Spanish cities, Madrid and Caceres. The results showed that roads with less congestion (higher average speeds) obtained better result for average energy consumption. The effectiveness of eco-driving techniques is clear in both, in large-congested cities and in small ones. The saving values achieved in both cities ranged between $5 \%$ and $12 \%$. Eco-driving was more efficient when driving on higher capacity roads and decreased with city size. Performing ecodrive in low capacity roads was less efficient because they usually are more congested.

These techniques were most effective in the smalluncongested city (Caceres). Their effectiveness in a large/ congested city like Madrid was less clear. Eco-driving was found to be no efficient on local, one-lane streets. However, on these roads, when the lane was duplicated (major arterial), there was a big reduction on consumption and emissions. Regarding the effects of fuel saving on higher capacity roads, they were similar to those obtained in a small city such as Caceres.

Figure 12 shows a graph with the conclusions from this research.

4.2. Policy Recommendations. Eco-driving is not a policy measure advisable for any road and urban context. In roads suffering chronic congestion problems, eco-driving could get worse the problem. However, in noncongested areas, it is clearly beneficial. This happens normally in cities like Caceres, where wider spread of eco-driving practice is recommended on any type of road, with substantial fuel savings and to a lesser extend $\mathrm{CO}_{2}$ emissions. In those cities, savings could be achieved in all type of roads and itineraries. On the contrary, in big cities, with more congestion levels, eco-driving policies should be customized; limiting speed on high capacity roads has proven to be a good measure to energy savings. In local roads, the problem is their capacity limit for not reaching the congestion threshold. Measures looking at solving bottlenecks and adding capacity such as traffic lights and parking regulation, dual carriageways, and bus priority lanes are recommended wherever possible, since they help to lower traffic congestion, facilitating also the efficient application of eco-driving techniques. What is universal-both for small and large cities-is that major arterial roads are the optimum road sections for recommending eco-driving. Therefore, public authorities should encourage training eco-driving at driving schools and awareness campaigns, as well as nonaggressive driving patterns [47].

4.3. Future Developments. Other papers have analysed ecodriving performance according to gender and driving experience [48]. Future research could combine those variables with what it has been analysed in this paper, comparing typology of roads and urban environment. Efficiency of eco-driving in professional courier drivers could be of interest as well. On the contrary, it would be necessary to analyse results when many drivers practice eco-driving in the same route, affecting traffic flow characteristics and road density. If the number of ecodrivers increases, the effects on emissions and fuel consumption could be jeopardized: simulation and real tests should be recommended.

\section{Appendix}

\section{Eco-Driving Course Content}

The course has two parts.

(i) Part 1. Theoretical class in a group. Duration $1 \mathrm{~h}$.

Technical operation of car engines, different regimes, and their impacts on fuel consumption.

Concept of eco-driving s and how to apply this technique in practice.

\section{(ii) Part 2. Individual practical class. Duration $1 \mathrm{~h}$.}

Each driver performs two driving sessions with a supervisor. First, each participant drives with his own style and the supervisor indicates what is wrong. Then, he starts to apply the lessons learned in Part 1, while the supervisor corrects every time according to the traffic situations.

Finally, a final discussion on how to perform eco-driving in each situation is presented in a practical way. 


\section{Data Availability}

The data used to support the findings of this study may be released upon application to the "Centro de Investigación del transporte," who can be contacted at Centro de Investigación del Transporte Universidad Politécnica de Madrid Escuela de Ingenieros de Caminos, Canales y Puertos c/ Profesor Aranguren, 328040 Madrid 913366656 (alessandra.boggiomarzet@upm.es and http://www.ecotraffic. transyt-projects.es).

\section{Conflicts of Interest}

There are no conflicts of interest.

\section{Acknowledgments}

This work was partly funded by the national R\&D programme (Ministerio de Economía y Competitividad) under the Eco-Traffic Project "Medición y Modelización de EcoDriving táctico y operacional.” Ref TRA2016-76485-R (AEI/ FEDER, UE). The authors would also like to thank Madrid and Caceres Council for their support in the data collection process.

\section{References}

[1] Government of Spain, "Estrategia Española de movilidad sostenible," 2010, https://www.fomento.es/estrategia-espan\% CC\%83ola-de-movilidad-sostenible.

[2] European Environment Agency, "National action across all sectors needed to reach greenhouse gas Effort Sharing targets," 2019, https://www.eea.europa.eu/publications/nationalaction-across-all-sectors.

[3] European Environment Agency, “Transport: increasing oil consumption and greenhouse gas emissions hamper EU progress towards environment and climate objectives," 2020, https://www.eea.europa.eu/themes/transport/term/ increasing-oil-consumption-and-ghg.

[4] United Nations, "Climate change conference COP 25," 2019, https://unfccc.int/cop25.

[5] European Environment Agency, "Trends and projections in europe 2018," EEA Report No 16/2018, European Environment Agency, Copenhagen, Denmark, 2018.

[6] Organisation for Economic Cooperation and Development and International Transport Forum Working Group, "Greenhouse gas reduction strategies in the transport sector," 2010, https://www.itf-oecd.org/sites/default/files/ docs/10ghgtrends.pdf.

[7] H. Xia, K. Boriboonsomsin, and K. M. Barth, "Dynamic ecodriving for signalized arterial corridors and its indirect network-wide energy/emissions benefits," Journal of Intelligent Transportation Systems, vol. 17, no. 1, pp. 31-41, 2013.

[8] K. Ahn and H. Rakha, "The effects of route choice decisions on vehicle energy consumption and emissions," Transportation Research Part D: Transport and Environment, vol. 13, no. 3, pp. 151-167, 2008.

[9] M. Sivak and B. Schoettle, "Eco-driving: strategic, tactical, and operational decisions of the driver that influence vehicle fuel economy," Transport Policy, vol. 22, pp. 96-99, 2012.

[10] Y. Huang, E. C. Y. Ng, J. L. Zhou, N. C. Surawski, E. F. C. Chan, and G. Hong, "Eco-driving technology for sustainable road transport: a review," Renewable and Sustainable Energy Reviews, vol. 93, pp. 596-609, 2018.

[11] M. S. Alam and A. McNabola, "A critical review and assessment of eco-driving policy \& technology: benefits \& limitations," Transport Policy, vol. 35, pp. 42-49, 2014.

[12] M. A. S. Kamal, M. Mukai, J. Murata, and T. Kawabe, "Model predictive control of vehicles on urban roads for improved fuel economy," IEEE Transactions on Control Systems Technology, vol. 21, no. 3, pp. 831-841, 2013.

[13] Y. Wang and A. Boggio-Marzet, "Evaluation of eco-driving training for fuel efficiency and emissions reduction according to road type," Sustainability, vol. 10, no. 11, p. 3891, 2018.

[14] A. Seedam, T. Satiennam, T. Radpukdee, W. Satiennam, and V. Ratanavaraha, "Motorcycle on-road driving parameters influencing fuel consumption and emissions on congested signalized urban corridor," Journal of Advanced Transportation, vol. 2017, Article ID 5859789, 6 pages, 2017.

[15] C. Chen, X. Zhao, Y. Yao, Y. Zhang, J. Rong, and X. Liu, "Driver's eco-driving behavior evaluation modeling based on driving events," Journal of Advanced Transportation, vol. 2018, Article ID 9530470, 12 pages, 2018.

[16] M. Barth, S. Mandava, K. Boriboonsomsin, and H. Xia, "Dynamic ECO-driving for arterial corridors," in Proceedings of the 2011 IEEE Forum on Integrated and Sustainable Transportation Systems, pp. 182-188, Vienna, Austria, June 2011.

[17] M. Zarkadoula, G. Zoidis, and E. Tritopoulou, "Training urban bus drivers to promote smart driving: a note on a Greek eco-driving pilot program," Transportation Research Part D: Transport and Environment, vol. 12, no. 6, pp. 449-451, 2007.

[18] US Department of Transportation, "Highway functional classification: concepts, criteria and procedure," 2013, https://www.fhwa.dot.gov/planning/processes/statewide/ related/highway_functional_classifications/fcauab.pdf.

[19] G. Velazquez, S. Kaplan, and A. Monzon, "Ex-ante and expost evaluation of a new transit information app: modeling use intentions and actual use," Transportation Research Record: Journal of the Transportation Research Board, vol. 2672, no. 50, pp. 56-65, 2018.

[20] Y. Wang and A. Monzon, "Economic crisis and its influences on the interaction between land use and transport in Madrid Region," Transportation Research Procedia, vol. 18, pp. 100107, 2016.

[21] J. F. Coloma, M. García, Y. Wang, and A. Monzón, "Green Eco-driving effects in non-congested cities," Sustainability, vol. 10, no. 2, p. 28, 2017.

[22] “OBD-Key," KBM Systems Ltd, London, UK, 2019, http:// www.obdkey.com/.

[23] I. J. Hawkins, Torque Pro and Lite, 7 St Pauls, Buckinghamshire, MK 16, UK, 2019, https://torque-bhp.com/.

[24] J. L. Jimenez-Palacios, "Understanding and quantifying motor vehicle emissions with vehicle specific power and TILDAS remote sensing," Massachusetts Institute of Technology, https://pdfs.semanticscholar.org/3219/ 147b53fafde8d4cb816ecf307a1e3eb665d6.pdf, Ph.D. Thesis, Department of Mechanical Engineering, Cambridge, MA, USA, 1998, https://pdfs.semanticscholar.org/3219/ 147b53fafde8d4cb816ecf307a1e3eb665d6.pdf, Ph.D. Thesis.

[25] R Foundation, "The R foundation for statistical computing," Vienna, Austria, 2019, https://www.r-project.org/.

[26] Esri España, "Emilio muñoz," Madrid, Spain, 2019, https:// www.esri.es/. 
[27] M. V. Faria, P. C. Baptista, T. L. Farias, and J. M. Pereira, "Assessing the impacts of driving environment on driving behavior patterns," Transportation, vol. 47, no. 3, pp. 1-27, 2020.

[28] P. Chen, C. Yan, J. Sun, Y. Wang, S. Chen, and K. Li, "Dynamic eco-driving speed guidance at signalized intersections: multivehicle driving simulator based experimental study," Journal of Advanced Transportation, vol. 2018, Article ID 6031764, 11 pages, 2018.

[29] H. Zhai, H. C. Frey, and N. M. Rouphail, "A vehicle-specific power approach to speed-and facility-specific emissions estimates for diesel transit buses," Environmental Science \& Technology, vol. 42, no. 1, pp. 7985-7991, 2008.

[30] H. Wang, L. Fu, Y. Zhou, and H. Li, "Modelling of the fuel consumption for passenger cars regarding driving characteristics," Transportation Research Part D: Transport and Environment, vol. 13, no. 7, pp. 479-482, 2008.

[31] E. Yao, Z. Yang, Y. Song, and T. Zuo, "Comparison of electric vehicle's energy consumption factors for different road types," Discrete Dynamics in Nature and Society, vol. 2013, Article ID 328757, 7 pages, 2013.

[32] M. Faria, T. Farias, and P. Baptista, "Driving behavior patterns: impacts on emissions and safety performance," in Proceedings of the NECTAR 2017 International Conference, Madrid, Spain, May 2017.

[33] S. C. Davis and R. G. Boundy, Energy Data Book 2019, Office of Energy Efficiency and Renewable Energy. U.S. Department of Energy, Washington, DC, USA, 37.2 edition, 2019.

[34] M. C. Coelho, H. C. Frey, N. M. Rouphail, H. Zhai, and L. Pelkmans, "Assessing methods for comparing emissions from gasoline and diesel light-duty vehicles based on microscale measurements," Transportation Research Part D: Transport and Environment, vol. 14, no. 2, pp. 91-99, 2009.

[35] J. F. Coloma, M. García, and Y. Wang, "Eco-driving effects depending on the travelled road. Correlation between fuel consumption parameters," Transportation Research Procedia, vol. 33, pp. 259-266, 2018.

[36] D. Lois, Y. Wang, A. Boggio-Marzet, and A. Monzon, "Multivariate analysis of fuel consumption related to ecodriving: interaction of driving patterns and external factors," Transportation Research Part D: Transport and Environment, vol. 72, pp. 232-242, 2019.

[37] C. C. Rolim, P. C. Baptista, G. O. Duarte, and T. L. Farias, "Impacts of on-board devices and training on light duty vehicle driving behavior," Procedia-Social and Behavioral Sciences, vol. 111, pp. 711-720, 2014.

[38] B. Beusen, S. Broekx, T. Denys et al., "Using on-board logging devices to study the longer-term impact of an eco-driving course," Transportation Research Part D: Transport and Environment, vol. 14, no. 7, pp. 514-520, 2009.

[39] H. K. Strömberg and I. C. M. Karlsson, "Comparative effects of eco-driving initiatives aimed at urban bus drivers-results from a field trial," Transportation Research Part D: Transport and Environment, vol. 22, pp. 28-33, 2013.

[40] K. Miller, L. G. Drumwright, A. Kostreba et al., "Applications for the environment: real-time information synthesis (AERIS). Applications state of the practice," https://rosap.ntl. bts.gov/view/dot/37285 Assessment Report Report no: FHWA-JPO-11-139, U.S. Department of Transportation, Washington, DC, USA, 2011, https://rosap.ntl.bts.gov/view/ dot/37285 Assessment Report Report no: FHWA-JPO-11139.
[41] C. Andrieu and G. S. Pierre, "Comparing effects of eco-driving training and simple advices on driving behavior," Procedia-Social and Behavioral Sciences, vol. 54, pp. 211-220, 2012.

[42] A. Garcia-Castro and A. Monzon, "Using floating car data to analyse the effects of its measures and eco-driving," Sensors, vol. 14, no. 11, pp. 21358-21374, 2014.

[43] F. Perez-Prada, A. Monzon, and C. Valdes, "Managing traffic flows for cleaner cities: the role of green navigation systems," Energies, vol. 10, no. 6, p. 791, 2017.

[44] D. Barić, G. Zovak, and M. Periša, "Effects of eco-drive education on the reduction of fuel consumption and $\mathrm{CO}_{2}$ emissions," Promet-Traffic and Transportation, vol. 25, no. 3, pp. 265-272, 2013.

[45] M. Barth and K. Boriboonsomsin, "Energy and emissions impacts of a freeway-based dynamic eco-driving system," Transportation Research Part D: Transport and Environment, vol. 14, no. 6, pp. 400-410, 2009.

[46] G. S. Larue, A. Rakotonirainy, S. Demmel, and H. Malik, "Fuel consumption and gas emissions of an automatic transmission vehicle following simple eco-driving instructions on urban roads," IET Intelligent Transport Systems, vol. 8, no. 7, pp. 590-597, 2014.

[47] H. Strömberg, I. C. M. Karlsson, and O. Rexfelt, "Eco-driving: drivers' understanding of the concept and implications for future interventions," Transport Policy, vol. 39, pp. 48-54, 2015.

[48] M. García, J. F. Coloma, and Y. Wang, "Eco-driving in small cities. Driving performance in relation to driver's profile," Transportation Research Procedia, vol. 33, pp. 267-274, 2018. 